\title{
Rebels hold their own in journal price war
}

Last August, the entire editorial board of the Elsevier journal Topology quit in a row over pricing. Now they are setting up a non-profit competitor to be published by the London Mathematical Society. The Journal of Topology, announced last week, will launch next January and will cost US\$570 per year, compared with Topology's \$1,665.

It's not the first such move. Over the past eight years, around a dozen cheap or openaccess journals have been created to compete directly with an expensive commercial journal, many by editorial boards that had quit the original publication in protest. So, do the cheaper journals fare better than their rivals?

As far as scientific credibility is concerned, the answer is often yes - many of the challengers have obtained impact factors (a measure of the citations its papers receive) higher than their competitor. For example, the Journal of Machine Learning Research, set up in 2001 by editors of Springer's Machine Learning, has a 2005 impact factor of 4.027. "That's the highest in artificial intelligence, automation and control, and ninth in all of computer science," says Leslie Pack Kaelbling, a researcher at the Massachusetts Institute of Technology in Cambridge and the journal's editor-in-chief. Machine Learning has a 2005 impact factor of just 3.1.

One of the first defections was Evolutionary Ecology Research, set up in 1999 by Michael Rosenzweig, a researcher at the University of Arizona in Tucson. He defected, along with the entire editorial board, from Evolutionary Ecology, then published by Wolters Kluwer. Rosenzweig had established the journal in 1987, but became disillusioned with price increases.

The new journal has survived, with the online version getting up to 80,000 page views a month and a $50 \%$ increase in its number of pages, says Rosenzweig. He says the journal pioneered the idea of allowing libraries to subscribe only to an electronic version. Although its impact factor of 1.61 lags behind Evolutionary Ecology's 1.77, he dismisses this as unimportant: "Impact factors are toxic for science and the journals that serve it."

Like many of the rebel journals, Evolutionary Ecology Research was set up with help from the Scholarly Publishing and Academic Resources Coalition (SPARC), which fosters greater access to the literature. Joan Birman of Columbia University in New York is on the editorial board of Geometry and Topology, another SPARC-supported journal. She says it "has done better than
"Despite scholarly success, the rebel journals often get poor support from libraries." we could have dreamed".

But despite scholarly success, the journals often get poor support from libraries. "Libraries have not given us anything like the support, via subscriptions, that mathematicians have given us via submissions," says Birman. "Subscriptions have been an uphill battle. Our journals are self-supporting, but just barely so."

Declan Butler

See www.nature.com/news/2007/070122/full/ 445351a.html for a table of rebel journal success. 